\title{
The Limitations of FDA Criteria: Inconsistencies with Clinical Practice, Findings, and Adult Criteria as a Barrier to Pediatric Implantation
}

\author{
Lisa R. Park, Au.D., ${ }^{1}$ Erika B. Gagnon, Au.D., ${ }^{1}$ and \\ Kevin D. Brown, M.D., Ph.D. ${ }^{1}$
}

Children require greater access to sound than adults as they are learning to communicate using hearing and spoken language. Yet when it comes to cochlear implant candidacy, currently approved Food and Drug Administration (FDA) criteria for adults are much less restrictive than those for children, allowing for greater levels of residual hearing and aided speech recognition in adults. Cochlear implant guidelines for children have changed very little in the 30 years since cochlear implants have been approved for pediatrics, and this lack of change has proven to be a barrier to implantation. Using evidence-based practice, centers have been providing off-label implantation for children who fall outside of current FDA criteria, including children with more residual hearing, children with single-side deafness younger than 5 years, and infants with bilateral profound loss younger than 9 months. The purpose of this article is to outline how these restrictions impede access to implants for children and describe the evidence supporting cochlear implantation in children who fall outside of current criteria.

\section{KEYWORDS: children, cochlear implant, criteria, indications}

The Food and Drug Administration (FDA) first approved cochlear implantation (CI) for children in 1990. Since then, adult candidates have enjoyed expansion in indications from postlingual profound losses at initial approval to the inclusion of hybrid indications of normal sloping to severe hearing loss. Paradoxically, the indications for children have changed very little in the past 30 years (Table 1). Generally, FDA indications are still
${ }^{1}$ Department of Otolaryngology/Head and Neck Surgery, The University of North Carolina at Chapel Hill, Durham, North Carolina.

Address for correspondence: Lisa R. Park, Au.D., The Children's Cochlear Implant Center at UNC, 5501 Fortunes Ridge Dr., Suite A, Durham, NC 27713 (e-mail: Lisa_Park@med.unc.edu).
Barriers to Cochlear Implant Access: Acknowledging the Challenges, Changing the Future; Guest Editor, Sarah Sydlowski, Au.D., Ph.D., M.B.A.

Semin Hear 2021;42:373-380. (C) 2021. Thieme. All rights reserved. Thieme Medical Publishers, Inc., 333 Seventh Avenue, 18th Floor, New York, NY 10001, USA DOI: https://doi.org/10.1055/s-0041-1739370. ISSN 0734-0451. 
Table 1 Summary of General Changes in FDA Criteria for Cochlear Implantation

\begin{tabular}{l}
\hline Changes in pediatric criteria \\
\hline 1985 \\
- Not yet approved for children \\
- Age: Two years and older \\
- Degree: Profound bilateral ( $\geq 90 \mathrm{~dB} \mathrm{HL}$ ) \\
- Speech perception: $0 \%$ \\
1998 \\
- Age: Reduced to 18 mo \\
- Degree: No change \\
- Speech perception: Less than $20 \%$
\end{tabular}

2000

- Age: Reduced to 12 mo

- Degree: Expanded to severe-to-profound for those 2 y and older

- Speech perception: Adjusted to include "lack of auditory progress" and <30\% open set M/LNT word scores

2014

- Age: No change

- Degree: No change

- Speech perception: No change

2019

- Age: No change

- Degree: Addition of single-side deafness and asymmetric hearing loss for ages $5+$ with less than 10 y of deafness

- Speech perception: No change 2020

- Age: Reduced to 9 mo

- Degree: No change

- Speech perception: No change

\section{Changes in adult criteria}

- Approved for post-lingually deafened adults aged 18 or older with profound bilateral hearing loss ( $\geq 90 \mathrm{~dB} \mathrm{HL}$ ) and no speech recognition skills

- Age: No change

- Degree: No change

- Speech perception: No change

- Age: Addition of pre-lingually deafened adults

- Degree: Expanded to severe-to-profound losses ( $\geq 70 \mathrm{~dB} H \mathrm{H}$ )

- Speech perception: $\leq 40 \%$ in the best aided condition

- Age: No change

- Degree: No change

- Speech perception: $\leq 50 \%$ correct in the ear to be implanted ( $\leq 60 \%$ in the best aided condition).

- Age: No change

- Degree: Normal-to-moderate low frequency hearing ( $<60 \mathrm{~dB} \mathrm{HL}$ ) sloping to severe ( $\geq 70 \mathrm{~dB} \mathrm{HL}$ ) for hybrid/EAS devices, moderate-to-profound for traditional devices.

- Speech perception: 10-60\% in the ear to be implanted and $<80 \%$ contralaterally

- Age: No change

- Degree: Addition of single-side deafness and asymmetric hearing loss with less than $10 \mathrm{y}$ of deafness

- Speech perception: No change

- Age: No change

- Degree: No change

- Speech perception: No change

Abbreviations: EAS, electric-acoustic stimulation; M/LNT, multisyllabic or standard lexical neighborhood test.

limited to severe to profound hearing loss for children who are relying on hearing to develop spoken language.

Larger volume centers have noted that the benefits expanded CI indications have brought to adults and neurotologists are routinely providing implants off-label to children who fall outside traditional criteria. ${ }^{1}$ These off-label surgeries include implantation in children below current age recommendations and those 
with better hearing than current guidelines stipulate in at least one ear. ${ }^{1,2}$ The American Academy of Otolaryngology - Head and Neck Surgery Position Statement on Pediatric CI Candidacy supports these practices. The statement endorses implantation in children with confirmed deafness who are as young as 6 months of age and children older than 12 months with a pure tone average (PTA) of $65 \mathrm{~dB}$ HL or poorer, ${ }^{3}$ which falls in the moderately severe range. ${ }^{4}$

Recent changes in FDA criteria for children have included a lowering in the age of implantation for bilaterally deaf infants to 9 months $s^{5}$ and implantation in cases of singleside deafness (SSD) for children 5 years of age or older. ${ }^{6}$ While these are celebrated achievements, they still do not go far enough to reflect practices supported by research and clinical practice. This article outlines current clinical practices in expansion of pediatric CI focusing on early intervention, degree of hearing loss, and SSD.

\section{EARLY INTERVENTION}

When CIs were first approved for children in 1990, toddlers needed to be at least 24 months of age to be considered for an implant. Eight years later, the age was reduced to 18 months, and 2 years later the age was lowered to the long-standing criteria of 12 months. It took 20 years for that criteria to move just 3 months younger. In 2020, the FDA approved a change in indications for the Nucleus 24 Cochlear Implant System (Cochlear Americas, Sydney, Australia) to include CI at 9 months of age. ${ }^{5}$ While a welcome and long overdue change, many would argue that it does not go far enough.

The Joint Committee on Infant Hearing (JCIH) has long set standards for intervention benchmarks for children who are deaf and hard of hearing. Their statements are what set the standard 1-3-6 guideline: calling for hearing screening by 1 month of age, appropriate evaluation by 3 months of age, and appropriate intervention established by 6 months of age. The most recent guidelines encourage states to strive toward a 1-2-3 guideline, bringing the age of appropriate intervention even lower to
3 months of age. ${ }^{7}$ These benchmarks stress the importance of very early intervention to promote language development that is in line with the parents' goals for their child. For children with no auditory brainstem response who are clear audiologic CI candidates, ${ }^{8}$ hearing aids do not provide enough access to sound for spoken language and would not fit the description of "appropriate intervention" for families who have spoken language goals for their child. Thus, CI at 9 months of age does not meet JCIH standards for these children.

Early auditory input with a CI can take advantage of neural plasticity in the developing infant brain. ${ }^{9,10} \mathrm{CI}$ in infants has been found to be a safe intervention under skilled providers. ${ }^{11-14}$ Earlier age at implantation has been associated with better outcomes in numerous studies ${ }^{14-24}$ and recent research has shown that implantation in younger than 9 months is advantageous when compared with those implanted between 9 and 12 months of age. ${ }^{16,23,24}$ Dettman and colleagues purport that implantation before 9 months of age provides the best option for optimal language development. ${ }^{16}$ Previous work therefore demonstrates the safety and utility of offering surgery to families of younger children with bilateral severe to profound hearing loss, rather than waiting for a specific time frame implied by FDA criteria.

\section{DEGREE OF HEARING LOSS}

Device labeling approved by the FDA differs among manufacturers. When strictly considering FDA-approved audiometric criteria, $\mathrm{Co}^{-}$ chlear Americas' (Sydney, Australia) most recent device lists pediatric candidacy as "severe to profound" bilateral loss for children 2 years and older, and profound bilateral loss for children younger than 2 years. There is no threshold definition in the device insert. ${ }^{25}$ MED-EL (Innsbruck, Austria) does provide more specific metrics in their SYNCHRONY device insert, defining candidacy for children aged 12 months and older as bilateral profound loss with thresholds of $90 \mathrm{~dB}$ or poorer at $1,000 \mathrm{~Hz}^{26}$ The insert for the HiResolution Ultra 3D implant (Advanced Bionics, Valencia, CA) states that children should have a profound bilateral loss of 
$\geq 90 \mathrm{~dB} \mathrm{HL} .{ }^{27}$ Candidacy for adults is substantially more lax. The same inserts define adult candidacy as a moderate to profound bilateral loss; however, adults can be considered for hybrid or electric-acoustic stimulation (EAS) devices. The Nucleus Hybrid L24 is approved for adults with severe to profound high-frequency loss, defined as typically including thresholds $\leq 60 \mathrm{~dB}$ HL from 125 through $500 \mathrm{~Hz}$ and an average of $\geq 75 \mathrm{~dB} \mathrm{HL}$ at 2,000, 3,000, and $4,000 \mathrm{~Hz}^{28}$ MED-EL lists their EAS system candidates as typically having normal to moderate low-frequency hearing and thresholds of $\geq 70 \mathrm{~dB} H \mathrm{HL}$ at 2,000 and above. Fig. 1 illustrates the least restrictive audiometric candidacy criteria for adults versus children.

Speech recognition and validation of hearing aid fitting is a vital piece of candidacy consideration. Hearing aid performance cannot be estimated by earphone or threshold measures alone ${ }^{29,30}$; hence, candidacy criteria include aided word recognition guidelines. These values also differ vastly between adults and children. For pediatrics, Cochlear Americas' labeling sets a limit of $\leq 30 \%$ words correct on a multisyllabic or standard lexical neighborhood test in the best aided condition. ${ }^{25,31}$ MED-EL and Advanced Bionics have the same tests with a lower standard of $\leq 20 \%{ }^{26,27}$ These guidelines thereby suggest that a child must miss 70 to $80 \%$ of very simple single words in a quiet environment in both ears before they qualify for a CI. In contrast, the least stringent adult criterion requires that only $40 \%$ of more difficult single word stimuli be missed before qualifying for an implant. For traditional adult candidates, Cochlear Americas' approved criterion is $\leq 50 \%$ on sentence materials in the ear to be implanted and hybrid/EAS criteria are $\leq 60 \%$ aided word recognition for both Cochlear and MED-EL. MED-EL specifies aided word recognition of $\leq 60 \%$ contralaterally and $\mathrm{Co}^{-}$ chlear indicates up to $80 \%$ aided word recognition contralaterally. ${ }^{26,28}$

These glaring discrepancies are troublesome and illogical considering that children need greater access to soft speech and high frequencies than adults. ${ }^{32,33}$ These criteria indicate that FDA-regulated clinical trials have shown CIs to be an effective treatment for adults with postlingually acquired hearing loss even when they have normal low-frequency thresholds and aided single word recognition scores as high as $60 \%$. Adults with such significant hearing levels and a fully developed spoken language system have shown that hearing aids may not be enough for communication; yet, pediatric criterion implies that we expect children to learn and access spoken language with much more significant levels of hearing loss. In addition, children with CIs average upward of
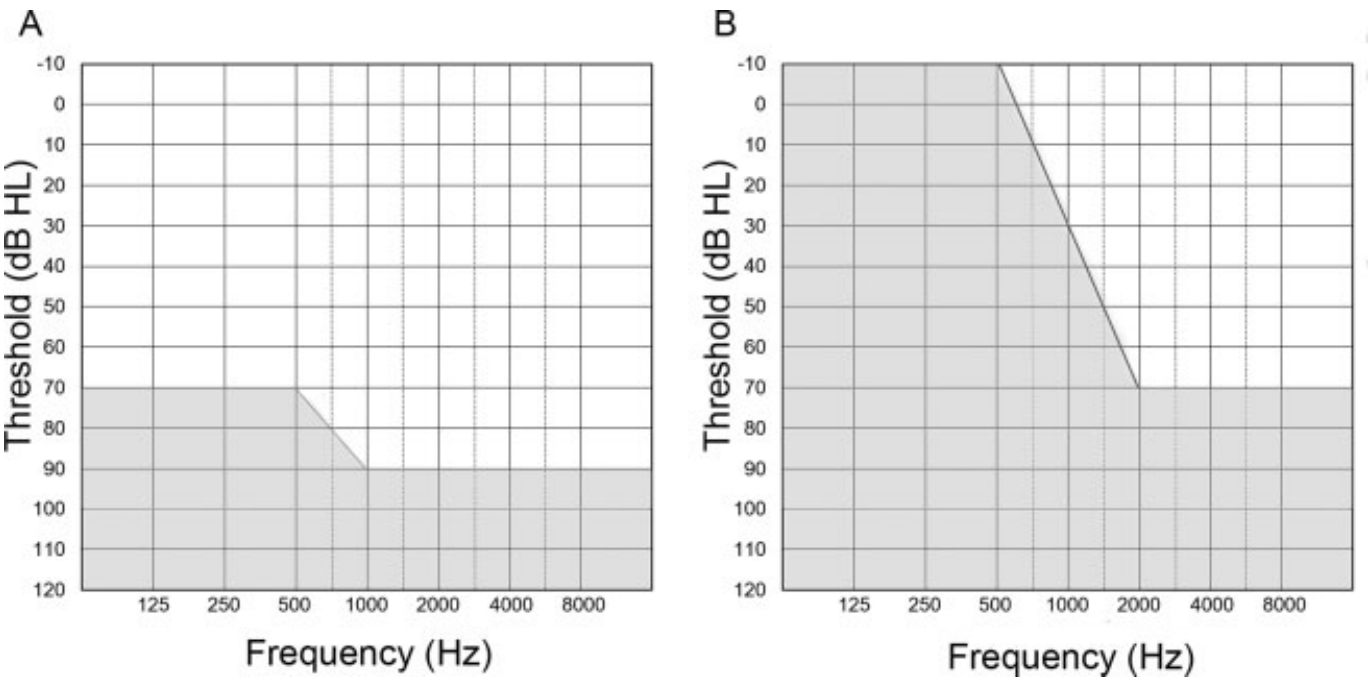

Figure 1 The least restrictive FDA candidacy criteria for children (A) and adults (B). Those with thresholds within the shaded area would be considered candidates for cochlear implantation under FDA guidelines. 
$70 \%$ word recognition in quiet environments, ${ }^{2}$ leaving a gap of more than $40 \%$ points between candidacy criteria with a hearing aid and what is achievable with a CI.

Science supports CI for children with more hearing than current FDA criteria allows. Pediatric studies on EAS use have shown beneficial outcomes when compared with preoperative hearing, ${ }^{34,35}$ but even without the use of EAS studies have shown that children with residual hearing benefit from CIs. Gratacap and colleagues demonstrated improved outcomes for children with residual hearing as opposed to preoperative hearing aid scores through a retrospective review. ${ }^{36}$ Similarly, Carlson and colleagues reported on 51 children with less severe hearing loss than current indications who derived significant benefit from CI. ${ }^{37}$ A landmark study from Leigh and colleagues in 2016 compared speech recognition performance of children using hearing aids to those of children with CIs and found that children with a PTA of greater than $60 \mathrm{~dB}$ HL have a $75 \%$ chance of greater benefit with a CI than a hearing aid. ${ }^{19}$ Children with steeply sloping hearing losses benefit as well. As early as 2007, Skarzynski and colleagues began presenting data on case series of children with normal low-frequency hearing and profound high-frequency hearing losses who benefited from CI. ${ }^{38}$ In 2017, Meredith and colleagues presented cases of children as young as 2.5 years with sloping hearing loss who derived significant benefit from CI within the first month of use, ${ }^{39}$ indicating that benefits can be experienced quite rapidly. Determination of candidacy may be challenging in children with residual hearing; however, studies support aided speech intelligibility index (SII) scores of less than 0.65 to be an appropriate benchmark for consideration, as these children are at risk for delays in language development due to lack of appropriate access to sound. ${ }^{29,40,41}$

\section{SINGLE-SIDE DEAFNESS}

The 2019 FDA labeling approval for implantation in cases of SSD in children aged 5 and older (MED-EL) was welcomed. Early studies and case reports have indicated benefits in chil- dren, ${ }^{42}$ particularly when it comes to hearing in noise ${ }^{43-47}$ and localization. ${ }^{43,48,49}$ The age limit of 5 years was likely set due to safety, as the clinical trial used for approval did not include young children. The FDA labeling carries a limitation of $\leq 10$ years of deafness, reflective of the importance of limiting auditory deprivation. Because of the known importance of neuroplasticity in producing good CI outcomes, reducing the age of implantation below 5 years would be advantageous. Auditory neuroplasticity is known to be greatly reduced after 7 years of age, ${ }^{50}$ and current FDA criteria would leave a brief 2-year window of potential benefit for children with congenital loss. Studies have indicated that children with SSD may experience neural reorganization that could impact their ability to integrate the CI signal with the better hearing ear if implantation is delayed to meet FDA criteria. ${ }^{48,51,52}$ While children with SSD who received implants at less than 5 years of age have shown positive outcomes for hearing in spatially separated noise ${ }^{47}$ and reduction of listening effort, ${ }^{53}$ the practice is still early in its evolution and the implications of age at surgery is not yet fully understood. Clinical trials involving young children with SSD are required to answer questions about the impact of age in this population.

Given the known importance of early implantation in children with bilateral hearing loss and known impact of auditory deprivation in the SSD population, implantation earlier than age 5 would likely result in better outcomes. Families, clinicians, and interventionists may express a desire to wait until a child is school age to see if they are experiencing difficulties in attention, behavior, language, or learning. While it seems plausible to offer implantation only to those known to have the most obvious impact from SSD, it is possible that these effects are the result of neural reorganization from years of unilateral input. If a child with SSD does not receive an implant until they exhibit signs of difficulty in elementary school, the window of maximal neuroplasticity may have passed. Achieving true binaural hearing and reversing the ill effects of SSD may be more difficult in children with congenital SSD who wait to receive a $\mathrm{CI}$. 


\section{CONCLUSIONS}

Pediatric CI criteria have changed very little in the 30 years since the devices were first approved. While the recent changes in FDA criteria are welcome, they do not offer implantation to all children who could benefit. The lower age level for bilaterally deaf infants is not in line with JCIH standards, audiometric criteria for children lag well behind adult criteria, and age limits for SSD are restrictive. While many CI centers recognize these discrepancies and routinely offer implantation offlabel for children, referring providers and smaller centers may not be aware of these practices. There is a misconception that labeling reflects best practice, which prevents referrals for CI evaluation and results in more insurance denials. These factors create additional barriers to appropriate care and delays in implantation. While the discrepancies between FDA criteria and actual practice must be resolved through clinical trials and amendments to criteria, they can be partially addressed by competent, confident recommendations for $\mathrm{CI}$ that align with best practice over outdated FDA or insurance guidance.

\section{CONFLICT OF INTEREST}

L.R.P. receives research grant support provided to the university from MED-EL Corporation. K.D.B. serves on the MED-EL Surgical Advisory Board.

\section{REFERENCES}

1. Carlson ML, O'Connell BP, Lohse CM, Driscoll CL, Sweeney AD. Survey of the American Neurotology Society on Cochlear Implantation: Part 2, Surgical and device-related practice patterns. Otol Neurotol 2018;39(01):e20-e27

2. Teagle HFB, Park LR, Brown KD, Zdanski C, Pillsbury HC. Pediatric cochlear implantation: a quarter century in review. Cochlear Implants Int 2019;20(06):288-298

3. American Academy of Otolaryngology Head and Neck Surgery. Position Statement: Pediatric Cochlear Implants. Published 2020. Accessed October 20, 2021 at: https:/www.entnet.org/content/ position-statement-pediatric-cochlear-implants
4. Clark JG. Uses and abuses of hearing loss classification. ASHA 1981;23(07):493-500

5. US Food and Drug Administration. Nucleus 24 Cochlear Implant System PMA Supplement Approval Letter. 2020 Accessed October 20, 2021 at: https://www.accessdata.fda.gov/cdrh_docs/pdf/ P970051S172A.pdf

6. US Food and Drug Administration. MED-EL Cochlear Implant System PMA Supplement Approval Letter. 2019 Accessed October 20, 2021 at: https://www.accessdata.fda.gov/cdrh_docs/pdf/ P000025S104A.pdf

7. The Joint Committee on Infant Hearing. Year 2019 position statement: Principles and guidelines for early hearing detection and intervention programs. J Early Hear Detect Interv 2019;42(02): $1-44$

8. Hang AX, Roush PA, Teagle HFB, et al. Is "no response" on diagnostic auditory brainstem response testing an indication for cochlear implantation in children? Ear Hear 2015;36(01):8-13

9. Kral A, Dorman MF, Wilson BS. Neuronal development of hearing and language: cochlear implants and critical periods. Annu Rev Neurosci 2019;42 (01):47-65

10. Kral A, Sharma A. Developmental neuroplasticity after cochlear implantation. Trends Neurosci 2012; 35(02):111-122

11. Roland JT Jr, Cosetti M, Wang KH, Immerman S, Waltzman SB. Cochlear implantation in the very young child: long-term safety and efficacy. Laryngoscope 2009;119(11):2205-2210

12. Deep NL, Purcell PL, Gordon KA, Papsin BC, Roland JT Jr, Waltzman SB. Cochlear implantation in infants: evidence of safety. Trends Hear 2021;25:23312165211014695

13. Hoff S, Ryan M, Thomas D, et al. Safety and effectiveness of cochlear implantation of young children, including those with complicating conditions. Otol Neurotol 2019;40(04):454-463

14. Miyamoto RT, Colson B, Henning S, Pisoni D. Cochlear implantation in infants below 12 months of age. World J Otorhinolaryngol Head Neck Surg 2018;3(04):214-218

15. Ching TYC, Dillon H, Button L, et al. Age at intervention for permanent hearing loss and 5-year language outcomes. Pediatrics 2017;140(03): e20164274

16. Dettman S, Choo D, Au A, Luu A, Dowell R. Speech perception and language outcomes for infants receiving cochlear implants before or after 9 months of age: use of category-based aggregation of data in an unselected pediatric cohort. J Speech Lang Hear Res 2021;64(03):1023-1039

17. Dettman SJ, Pinder D, Briggs RJS, Dowell RC, Leigh JR. Communication development in children who receive the cochlear implant younger than 
12 months: risks versus benefits. Ear Hear 2007;28 (2, Suppl):11S-18S

18. Leigh J, Dettman S, Dowell R, Briggs R. Communication development in children who receive a cochlear implant by 12 months of age. Otol Neurotol 2013;34(03):443-450

19. Leigh JR, Dettman SJ, Dowell RC. Evidencebased guidelines for recommending cochlear implantation for young children: audiological criteria and optimizing age at implantation. Int J Audiol 2016;55(February, Suppl 2):S9-S18

20. Wie OB, Torkildsen JVK, Schauber S, Busch T, Litovsky R. Long-term language development in children with early simultaneous bilateral cochlear implants. Ear Hear 2020;41(05):1294-1305

21. Tajudeen BA, Waltzman SB, Jethanamest D, Svirsky MA. Speech perception in congenitally deaf children receiving cochlear implants in the first year of life. Otol Neurotol 2010;31(08): 1254-1260

22. Niparko JK, Tobey EA, Thal DJ, et al; CDaCI Investigative Team. Spoken language development in children following cochlear implantation. JAMA 2010;303(15):1498-1506

23. Karltorp E, Eklöf M, Östlund E, Asp F, Tideholm B, Löfkvist U. Cochlear implants before 9 months of age led to more natural spoken language development without increased surgical risks. Acta Paediatr 2020;109(02):332-341

24. Chweya CM, May MM, DeJong MD, et al. Language and audiological outcomes among infants implanted before 9 and 12 months of age versus older children: a continuum of benefit associated with cochlear implantation at successively younger ages. Otol Neurotol 2021;42(05):686-693

25. Cochlear Americas. Cochlear ${ }^{\mathrm{TM}}$ Nucleus ${ }^{\circledR} \mathrm{CI} 612$ Cochlear Implant with Contour Advance ${ }^{\circledR}$ Electrode. Cochlear Ltd; 2020

26. MED-EL Corporation. Mi1250 SYNCHRONY 2 Cochlear Implant. MED-EL Elektromedizinische Geräte $\mathrm{GmbH} ; 2020$

27. Advanced Bionics. HiResolution ${ }^{\mathrm{TM}}$ Bionic Ear System, HiRes ${ }^{\mathrm{TM}}$ Ultra 3D Cochlear Implant. 2018

28. Cochlear Americas. Nucleus ${ }^{\circledR}$ Hybrid ${ }^{\text {TM }}$ L24 Cochlear Implant. Cochlear Ltd; 2021

29. Stiles DJ, Bentler RA, McGregor KK. The Speech Intelligibility Index and the pure-tone average as predictors of lexical ability in children fit with hearing AIDS. J Speech Lang Hear Res 2012;55 (03):764-778

30. McRackan TR, Ahlstrom JB, Clinkscales WB, Meyer TA, Dubno JR. Clinical implications of word recognition differences in earphone and aided conditions. Otol Neurotol 2016;37(10):1475-1481

31. Kirk KI, Pisoni DB, Osberger MJ. Lexical effects on spoken word recognition by pediatric cochlear implant users. Ear Hear 1995;16(05):470-481
32. McCreery RW, Stelmachowicz PG. Audibilitybased predictions of speech recognition for children and adults with normal hearing. J Acoust Soc Am 2011;130(06):4070-4081

33. Ching TY, Dillon H, Byrne D. Speech recognition of hearing-impaired listeners: predictions from audibility and the limited role of high-frequency amplification. J Acoust Soc Am 1998;103(02):1128-1140

34. Park LR, Teagle HFB, Gagnon E, Woodard J, Brown KD. Electric-acoustic stimulation outcomes in children. Ear Hear 2019;40(04):849-857

35. Wolfe J, Neumann S, Schafer E, Marsh M, Wood M, Baker RS. Potential benefits of an integrated electric-acoustic sound processor with children: a preliminary report. J Am Acad Audiol 2017;28(02): 127-140

36. Gratacap M, Thierry B, Rouillon I, Marlin S, Garabedian N, Loundon N. Pediatric cochlear implantation in residual hearing candidates. Ann Otol Rhinol Laryngol 2015;124(06):443-451

37. Carlson ML, Sladen DP, Haynes DS, et al. Evidence for the expansion of pediatric cochlear implant candidacy. Otol Neurotol 2015;36(01):43-50

38. Skarzynski H, Lorens A, Piotrowska A, Anderson I. Partial deafness cochlear implantation in children. Int J Pediatr Otorhinolaryngol 2007;71(09): 1407-1413

39. Meredith MA, Rubinstein JT, Sie KCY, Norton SJ. Cochlear implantation in children with postlingual progressive steeply sloping high-frequency hearing loss. J Am Acad Audiol 2017;28(10):913-919

40. Leal C, Marriage J, Vickers D. Evaluating recommended audiometric changes to candidacy using the speech intelligibility index. Cochlear Implants Int 2016;17(Suppl 1):8-12

41. Tomblin JB, Harrison M, Ambrose S, Walker E, Oleson J, Moeller MP. Language outcomes in young children with mild to severe hearing loss. Ear Hear 2015;36(Suppl 1(1)):76S-91S

42. Benchetrit L, Ronner EA, Anne S, Cohen MS. Cochlear implantation in children with singlesided deafness: a systematic review and meta-analysis. JAMA Otolaryngol Head Neck Surg 2021; 147(01):58-69

43. Ehrmann-Mueller D, Kurz A, Kuehn H, et al. Usefulness of cochlear implantation in children with single sided deafness. Int J Pediatr Otorhinolaryngol 2020;130(September 2019): 109808. Doi: 10.1016/j.ijporl.2019.109808

44. Sladen DP, Frisch CD, Carlson ML, Driscoll CLW, Torres JH, Zeitler DM. Cochlear implantation for single-sided deafness: a multicenter study. Laryngoscope 2017;127(01):223-228

45. Wesarg T, Arndt S, Wiebe K, et al. Speech recognition in noise in single-sided deaf cochlear implant recipients using digital remote wireless microphone technology. J Am Acad Audiol 2019; 30(07):607-618 
46. Zeitler DM, Sladen DP, DeJong MD, Torres JH, Dorman MF, Carlson ML. Cochlear implantation for single-sided deafness in children and adolescents. Int J Pediatr Otorhinolaryngol 2019;118 (January):128-133

47. Park LR, Dillon MT, Buss E, O'Connell BP, Brown $\mathrm{KD}$. Spatial release from masking in pediatric cochlear implant recipients with single-sided deafness. Am J Audiol 2021. Doi: 10.1044/2020_AJA-20-00119

48. Arndt S, Prosse S, Laszig R, Wesarg T, Aschendorff A, Hassepass F. Cochlear implantation in children with single-sided deafness: does aetiology and duration of deafness matter? Audiol Neurotol 2015;20(Suppl 1):21-30

49. Távora-Vieira D, Rajan GP. Cochlear implantation in children with congenital and noncongenital unilateral deafness. Otol Neurotol 2015;36(08): 1457-1458
50. Sharma A, Dorman MF, Spahr AJ. A sensitive period for the development of the central auditory system in children with cochlear implants: implications for age of implantation. Ear Hear 2002;23 (06):532-539

51. Rauch AK, Arndt S, Aschendorff A, et al. Longterm results of cochlear implantation in children with congenital single-sided deafness. Eur Arch Otorhinolaryngol 2021;278(09):3245-3255

52. Gordon K, Henkin Y, Kral A. Asymmetric hearing during development: the aural preference syndrome and treatment options. Pediatrics 2015;136(01): 141-153

53. Lopez EM, Dillon MT, Park LR, et al. Influence of cochlear implant use on perceived listening effort in adult and pediatric cases of unilateral and asymmetric hearing loss. Otol Neurotol 2021;42(09): e1234-e1241 